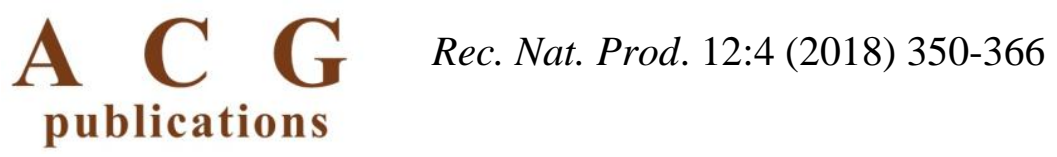

\title{
Evaluation of the Wound Healing Properties of Luteolin Ointments on Excision and Incision Wound Models in Diabetic and Non-Diabetic Rats
}

\author{
Yusuf Ozay $^{1 \oplus}$, Sevda Guzel ${ }^{2 \odot *}$, Ibrahim Halil Erdogdu ${ }^{3 \odot}$, Zuhal Yildirim $^{4 \odot}$, \\ Burcin Pehlivanoglu $^{5 \odot}$, Bilge Aydın Turk ${ }^{5 \odot}$ and Sinan Darcan ${ }^{6 \odot}$ \\ ${ }^{I}$ Department of Medical Biology, Faculty of Medicine, Adiyaman University, Adiyaman, Türkiye \\ ${ }^{2}$ Department of Pharmacognosy, Faculty of Pharmacy, Mersin University, Mersin, Turkey \\ ${ }^{3}$ Department of Pathology, Adnan Menderes University, Aydin, Türkiye \\ ${ }^{4}$ Etimesgut Public Health Laboratory, Etimesgut, Ankara, Türkiye \\ ${ }^{5}$ Department of Pathology, Adiyaman University, Training and Research Hospital, Adiyaman Türkiye \\ ${ }^{6}$ Gediz Vocational School of Health Services, Dumlupinar University, Kütahya, Türkiye
}

(Received August 07, 2017; Revised November 09, 2017; Accepted November 25, 2017)

\begin{abstract}
Luteolin, which is structurally classified under the flavonoids, is naturally distributed abundant among medicinal plants, vegetables and fruits. The wound healing effects of Luteolin ointments were evaluated for incision and excision wound models on non-diabetic and Streptozotocin induced diabetic rats by using macroscopical, biomechanical, biochemical and histopathological methods. Two different concentrations $(0.5 \%$ and $1 \%(\mathrm{w} / \mathrm{w}))$ of the Luteolin ointment were prepared with the mixture of glycol stearate:propylene glycol:liquid paraffin (3:6:1) and $0.5 \mathrm{~g}$ of the ointments were applied topically on wounds once daily for 7 and 14 days. During the experiments, wounds were visually observed, photographically documented and wound areas were measured. After 7 and 14 days treatment, animals were sacrificed under anesthesia and hydroxyproline measurement and biomechanical analysis were performed. Histopathology of the wound area was evaluated considering features of re-epithelialization, thickness of the granulation tissue, angiogenesis, presence of inflammation, number of mast cells. Outcomes of this study revealed that Luteolin ointments improved wound healing process of skin tissue both in non-diabetic and diabetic wounds. The best wound healing activity was observed in incision and excision wounds (97.6\%, 96.1\%, respectively) treated with $0.5 \%$ (w/w) Luteolin ointment on day 14 according to macroscopic results.
\end{abstract}

Keywords: Wound healing; luteolin; flavonoid; diabetes mellitus; rat. (C) 2018 ACG Publications. All rights reserved.

\section{Introduction}

Wounds are described as physical or thermal injuries that result in a breaking or opening of the skin surface which causes a disruption of the normal skin anatomy and function [1,2]. In routine life,

*Corresponding author: E-Mail: guzelsevda@ mersin.edu.tr; Phone: +90 5531263692 Fax:0324 3413022

The article was published by ACG Publications 
because of accidents and fires millions of people suffer from wounds, burns and cuts, therefore wounds, especially non-healing wounds, have became serious health care problem worldwide [3-5]. Because of different biological process wounds are categorized under various groups such as chronic and acute [4-6]. Most chronic wounds are associated with some illnesses including Diabetes mellitus (DM) [6-8] which is one of the most common disease worldwide [8,9]. In the United States, approximately 29.1 million people suffer from DM [10] and $15 \%$ of patients with DM complain from serious complications such as chronic ulcers $[8,10]$ which are characterized as impaired or non-healing wounds [9-11].

After occurring of the damage, wound repair is started as a normal biological process [12] which contains dynamic and multifaceted wound healing steps. These steps can be characterized into four highly programmed phases such as hemostasis, inflammation, proliferation and remodeling [2,6, 12-16]. All phases of healing must occur in suitable sequence for successful healing as a natural phenomenon $[6,12,13]$ but sometimes complex multifactorial process of wound healing can be delayed or failed by unwanted effects such as presence of free radicals [12,17] or microbial infections $[5,12,16,17]$.

Many synthetic drugs are used for treatment of wounds but expensive cost and adverse effects like allergic reactions and drug resistance limit the usage of them. Because of these reasons alternative treatment approaches are needed for wound healing [3]. The use of medicinal plants or their bioactive components which are responsible for the pharmacological effects of them are opening a new strategies for the treatment of wounds $[4,18]$.

Flavonoids known as bioactive compounds with polyphenolic structure are widely distributed in plant kingdom [19]. Literature data indicated that more than 8000 individual flavonoids [18] have been identified and classified into various sub-groups including flavonols, flavones, flavanols, flavanones, isoflavones [18,19]. Moreover, antioxidant [18,20], anti-inflammatory, anticancer $[18,20,21]$, neuro-protective and cardioprotective effects [18] of these components have been reported in many studies.

Luteolin (3',4',5,7-tetrahydroxyflavone), which is naturally distributed among several plant species such as medicinal plants, vegetables and fruits $[18,21,22]$, is structurally classified under the group of flavones [18-20]. Presence of hydroxyl moieties and 2-3 carbon double bond are responsible for its several biochemical and pharmacological activities $[18,19]$ like anti-inflammatory, antioxidant [6,18-22], anticancer [18,22], antimicrobial [19,22], anti-allergic [22], anti-diabetic [19]. These evidence indicated that many biological activities of Luteolin (e.g. antioxidant, anti-inflammatory, antimicrobial etc.) can be supported for ideal wound healing process in persistent dermal wounds, therefore, the present study aimed to evaluate the in vivo wound healing potential of Luteolin by using macroscopical, biochemical, biomechanical and histopathological methods on excision and incision dermal wounds of diabetic and non-diabetic rats.

\section{Materials and Methods}

\subsection{Luteolin Ointment Processing}

Simple ointment base was prepared according to the method mentioned Suntar et. al. (2012) by using glycol stearate:propylene glycol:liquid paraffin (3:6:1) [23] for enhancing the bioavailability of Luteolin which has poor water solubility. The ointment base increased the solubility of the tested material and were helped to get a homogeneous mixture with enhanced penetration capacity [24, 25]. An appropriate amount of Luteolin (LUT) (Sigma Chemical Co. (USA)) was added in this mixture to prepare for $0.5 \%$ and $1 \%(\mathrm{w} / \mathrm{w})$ Luteolin test ointments. The placebo and diabetic placebo-vehicle groups were topically treated with the mixture of glycol stearate:propylene glycol:liquid paraffin in the ratio of 3:6:1. During the experiments $0.5 \mathrm{~g}$ of the ointments were topically applied on wound areas once daily throughout 7 and 14 days. 


\subsection{Animals and Experimental Protocol}

Healthy young male Wistar rats weighing between 180 and $240 \mathrm{~g}$ at the same age were selected for this study (n: 112). The animals were obtained from Animal Production Laboratory of Faculty of Arts and Sciences, Dumlupinar University, Kutahya, Turkey. The animals were housed individually in cages under standard laboratory conditions (light/dark cycle of $12 \mathrm{~h} / 12 \mathrm{~h}$ at $25^{\circ} \mathrm{C} \pm 3$ ${ }^{\circ} \mathrm{C}$ with 50-70\% humidity) and during the experimental periods (7 and 14 days) fed with standard pellet diet and water ad libitum. Experimental protocol was performed with the acceptance of Institutional Animal Ethics Committee of Dumlupinar University (Reg. No. 2012/8.1). Two main groups (diabetic and non-diabetic groups) were designed for this study and each main group was randomly divided into four groups comprising fourteen animals (in each group seven animals (n:7) used for 7-day applications and seven animals (n:7) used for 14-day applications) in each group (Table 1).

Table 1. Experimental design of animal groups

\begin{tabular}{|c|c|c|}
\hline \multicolumn{3}{|r|}{ Non-Diabetic groups (n: 56) } \\
\hline \multirow{6}{*}{ Group 1} & G1 & Control (n:14)* \\
\hline & & (Non-treated group) \\
\hline & G2 & Placebo group-vehicle (n:14)* \\
\hline & & (Treated with glycol stearate:propylene glycol:liquid paraffin (3:6:1) mixture) \\
\hline & G3 & $0.5 \%(\mathrm{w} / \mathrm{w})$ Luteolin ointment treated non-diabetic group $(\mathrm{n}: 14)^{*}$ \\
\hline & G4 & $1 \%(\mathrm{w} / \mathrm{w})$ Luteolin ointment treated non-diabetic group $(\mathrm{n}: 14)^{*}$ \\
\hline
\end{tabular}

Diabetic groups (n: 56)

\begin{tabular}{ccl}
\hline & G5 & $\begin{array}{l}\text { Diabetic control-(n:14)* } \\
\text { (Non-treated group) }\end{array}$ \\
Group 2 & G6 & $\begin{array}{l}\text { Diabetic placebo group-vehicle (n:14)* } \\
\text { (Treated with glycol stearate:propylene glycol:liquid paraffin ( 3:6:1) mixture) }\end{array}$ \\
& G7 & $\begin{array}{l}0.5 \%(w / w) \text { Luteolin ointment treated diabetic group (n:14)* } \\
\text { G8 }\end{array}$ \\
$1 \%(w / w)$ Luteolin ointment treated diabetic group (n:14) *
\end{tabular}

*n:7 for 7-day applications; n:7 for 14-day applications

\subsection{Induction of Diabetes mellitus}

DM was induced by a single dose intraperitoneal (i.p.) injection of Streptozotocin (STZ) (Sigma Chemical Co. (USA)) (45 mg/kg) freshly prepared in saline. 3 days after the STZ injection glucose levels were defined by using rapid glucometer (Bayer, Germany) and animals with blood glucose levels above $300 \mathrm{mg} / \mathrm{dL}$ were considered as diabetic and chosen for the study.

\subsection{Anesthesia}

The anesthetics xylazine hydrochloride and ketamine hydrochloride were used intraperitoneally for the purpose of anesthesia with the doses of $10 \mathrm{mg} / \mathrm{kg}$ and $25 \mathrm{mg} / \mathrm{kg}$, respectively.

\subsection{Wound Models}

Under anesthesia surgical applications of skin tissue wound models were performed. Dorsal aspect of each anesthetic animal was shaved then wound area was cleaned by using ethanol (70\% $(\mathrm{v} / \mathrm{v}))$. 


\subsubsection{Excision Wound Model}

For monitoring wound contraction and wound closure time, the open excision-type wound was created by biopsy punch on the dorsal interscapular region of the each rat with $1.5 \mathrm{~cm}$ diameter in a circular manner with the removal of skin. The excisional wounds were left open after surgical applications [26]. The Luteolin ointments and the vehicle were topically applied once a day throughout 7 and 14 days. On day 8 randomly selected seven animals in each group were killed under anesthesia for evaluating 7-day applications. The remaining seven animals in each group were continued to applied topically with Luteolin ointments and the vehicle for 14 days. On day 15 these animals were killed under anesthesia for evaluating 14-day applications.

\subsubsection{Incision Wound Model}

For biomechanical tests, the incisional wound was created from $2 \mathrm{~cm}$ posterior to the excisional wound with $4 \mathrm{~cm}$ in length then each $1 \mathrm{~cm}$ apart three surgical sutures were placed [23]. The Luteolin ointments and the vehicle were topically applied once a day throughout 7 and 14 days. On the 7th post-wound day the sutures were removed and on day 8 randomly selected seven animals in each group were killed under anesthesia for evaluating 7-day applications. The remaining seven animals in each group were continued to apply topically with Luteolin ointments and the vehicle for 14 days. On the 14th post-wound day all the sutures were removed and on day 15 these animals in each group were killed under anesthesia for evaluating 14-day applications.

After 7 and 14 days application periods tissue samples were isolated from the skin of each tested animal for the further examinations.

\subsection{Macroscopical Study}

After wound creation on day 0, wounds were photographed by using a camera (Spot Insight QE, Diagnostic Instruments, USA) under anesthesia and the rats with scarred skin tissue were placed individually in the cages. After 7 and 14 days applications, wounds were photographed then wound areas on days 0, 7 and 14 were evaluated with SPOT Advanced (Diagnostic Instruments) program in order to determine wound contraction. Briefly, the degrees of healing of the incision and excision wounds were evaluated by measuring the length and surface of wounds using graph paper on day 7 and on day 14 after wound creation and wound healing ratio was calculated for each animal with the equation giving below [26].

Wound healing ratio (\%): $100 \times$ (1- specific day wound size/ initial wound size) [26].

\subsection{Biomechanical Study}

At the end of the experiments, isolated incision wound $(8 \times 20 \mathrm{~mm})$ tissues of all tested groups were put in to Ringer solution ( $\mathrm{pH} 7.4,15 \mathrm{~min}$.) and stored at $-20{ }^{\circ} \mathrm{C}$ until biomechanical analysis. Tensiometer (BIOPAC MP30 Acq. (Santa Barbara, USA)) was used for measuring tensile strength, cross section areas were determined and the sections were subjected to a tensile test. Tensile strength of all samples were evaluated by a biomechanical module $(1 \mathrm{~mm} / \mathrm{s}$ tensile stretching speed, 5 $\mathrm{g} / \mathrm{s}$ stretching force, $2.5 \mathrm{~kg}$ max force) compatible with BIOPAC MP30 Acq. [27,28].

\subsection{Hydroxyproline Measurement}

Samples were weighed, frozen, lyophilized and pulverized, respectively. Then they were dissolved in $1 \mathrm{~mL}$ of isopropyl alcohol $(50 \%(\mathrm{v} / \mathrm{v}))$ and hydrolysed. Chloramine-T was added on twenty-five microlitres of this hydrolysate. $10 \mathrm{~min}$. later, the mixture was incubated at $50{ }^{\circ} \mathrm{C}$ for 90 


\section{Wound healing properties of Luteolin}

min. after adding $1 \mathrm{~mL}$ Ehrlich's reagent. After the reaction, color changes were measured by using spectrophotometer (Shimadzu UV 1601, Shimadzu, Tokyo, Japan) under $560 \mathrm{~nm}$ wave-length. Additionally, different concentrations of hydroxyproline standard $(0.2,0.4,0.6,0.8,1.2$ and $1.6 \mu \mathrm{g}$ ) were tested under the same conditions. Sample concentrations were calculated by the help of standard curve. Results were calculated as $\mu \mathrm{g} / \mathrm{mg}$ dry weight of tissues [29].

\subsection{Histopathological Study}

The skin specimens of all tested groups were collected for histopathological studies at the end of the study (on day 7 and 14). Hematoxylin eosin (HE), Van Gieson (VG) and Toluidine blue (TB) staining methods were used for evaluation of histopathological changes of wound site. Firstly, tissue samples fixed in formalin $(10 \%)$ were embedded in paraffin. Then tissue sections with $5 \mu \mathrm{m}$ thickness were taken and stained with HE, VG and TB. Finally, under a light microscope (Olympus, Japan) all samples were examined [30]. Incisional and excisional tissue samples were evaluated for some criteria such as re-epithelialization, angiogenesis, thickness of granulation tissue, degree of inflammation, number of mast cells (TB staining was used for determination of mast cells), extent of dermal inflammation, presence of fibrosis and collagen deposition (VG staining was used for collagen deposition).

Results were scored as follow:

a. Re-epithelialization was evaluated as 0 (no re-epithelialization), 1 (mild: less than $50 \%$ of the wound), 2 (moderate: > $50 \%$ of the wound) and 3 (complete re-epithelialization) according to the previously reported criteria [31].

b. The granulation tissue thickness was scored between 0 and 3, and the score decreased as the granulation tissue matured.

c. Angiogenesis was scored as 0 (no angiogenesis), 1 ( $<5$ vessels per one high power field), 2 (6-10 vessels per one high power field) and 3 (more than 10 vessels per one high power field [32].

d. Presence of inflammation was evaluated as 0 (no dermal inflammation), 1 (presence of giant cells, lymphocytes and plasma cells), 2 (neutrophils as well as cells in score 1) and 3 (micro abscess formation) [33].

e. Dermal inflammation was evaluated according to the depth (0: no dermal inflammation, 1: in superficial dermis, 2: in reticular dermis and 3: involving subcutaneous fat tissue).

f. The number of mast cells per one high power field was recorded. Collagen deposition was scored between 0 and 3 [32].

g. Absence and presence of fibrosis were indicated as 0 and 1, respectively.

\subsection{Statistical Analysis}

SPSS 16 was used for data analysis. For 112 rats, data represented as the mean \pm S.D. and ANOVA test was chosen for data evaluation. Values with $\mathrm{P}<0.05$ and $\mathrm{P}<0.01$ were found statistically significant.

\section{Results and Discussion}

\subsection{Macroscopic Study}

During the experiments, wound healing periods (day 0,7 and 14) of non-diabetic and diabetic rats were photographed for excisional and incisional skin wounds (Figure 1,2a and 2b), then wound size was measured using Spot program and wound healing ratio was calculated for each tested animal. Wound healing ratio of all tested groups were given in Table 2. For excision wounds, after 7-day application wound healing ratio of Luteolin ointments $(0.5 \%$ and $1 \%(\mathrm{w} / \mathrm{w}))$ treated with nondiabetic groups (G3: 80.4\%; G4: 77.2\%, respectively) and diabetic groups (G7: 56.1\%; G8: $61.0 \%$, 
respectively) were found statistically significant $(\mathrm{P}<0.05)$ when compared with the control and vehicle groups. After 14-day application wound healing ratio of Luteolin ointments $(0.5 \%$ and $1 \%(\mathrm{w} / \mathrm{w}))$ treated with non-diabetic groups (G3: 96.1\%; G4: 95.5\%, respectively) and diabetic groups (G7: 81.8 $\%$; G8: $79.5 \%$, respectively) were found statistically significant $(\mathrm{P}<0.05)$. For incision wounds, at the end of 7-day application wound healing ratio of Luteolin ointments $(0.5 \%$ and $1 \%(\mathrm{w} / \mathrm{w}))$ treated with non-diabetic groups (G3: $64.4 \%$; G4: $65.8 \%$, respectively) and diabetic groups (G7: 46.5 \%; G8: $44.2 \%$, respectively) were found statistically significant when compared with the control and vehicle groups $(\mathrm{P}<0.05)$. Additionally, when all tested groups compared between each other for 14-day application, wound healing ratio of Luteolin ointments $(0.5 \%$ and $1 \%(\mathrm{w} / \mathrm{w}))$ treated with nondiabetic groups (G3: 97.6\%; G4: $97.4 \%$, respectively) and diabetic groups (G7: 89.5\%; G8: 88.9 \%, respectively) were found statistically significant $(\mathrm{P}<0.05)$.

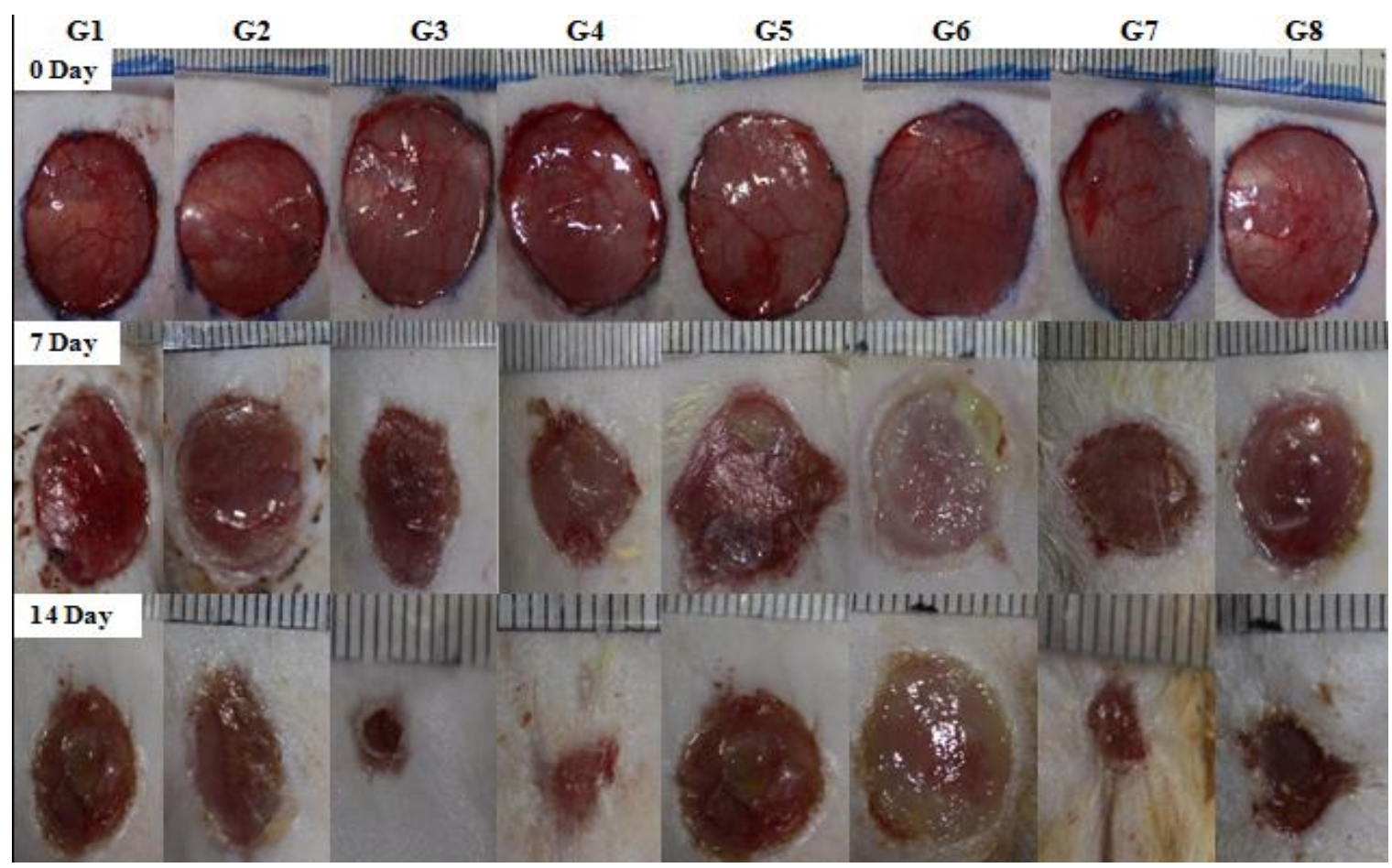

Figure 1. Macroscopic view of excision wounds of non-diabetic and diabetic groups treated with Luteolin (LUT) ointments for 7 and 14 days. (G1: Control, G2: Vehicle, G3: $0.5 \%$ LUT, G4: 1 \% LUT; G5: DM-Control, G6: DM-Vehicle, G7: DM-0.5 \% LUT, G8: DM-1 \%LUT)

\subsection{Biomechanical Study}

Luteolin ointments $(0.5 \%$ and $1 \%(\mathrm{w} / \mathrm{w}))$ applied daily for 7 and 14 days and tensile strength of all incision wound tissues were measured (Table 3). Tensile strength of Luteolin ointments treated non-diabetic and diabetic groups (G3; G4 and G7; G8, respectively) on $7^{\text {th }}$ and $14^{\text {th }}$ days showed significant differences when comparing with the control and vehicle groups (G1; G2 and G5; G6, respectively) $(\mathrm{P}<0.05)$. 
Wound healing properties of Luteolin

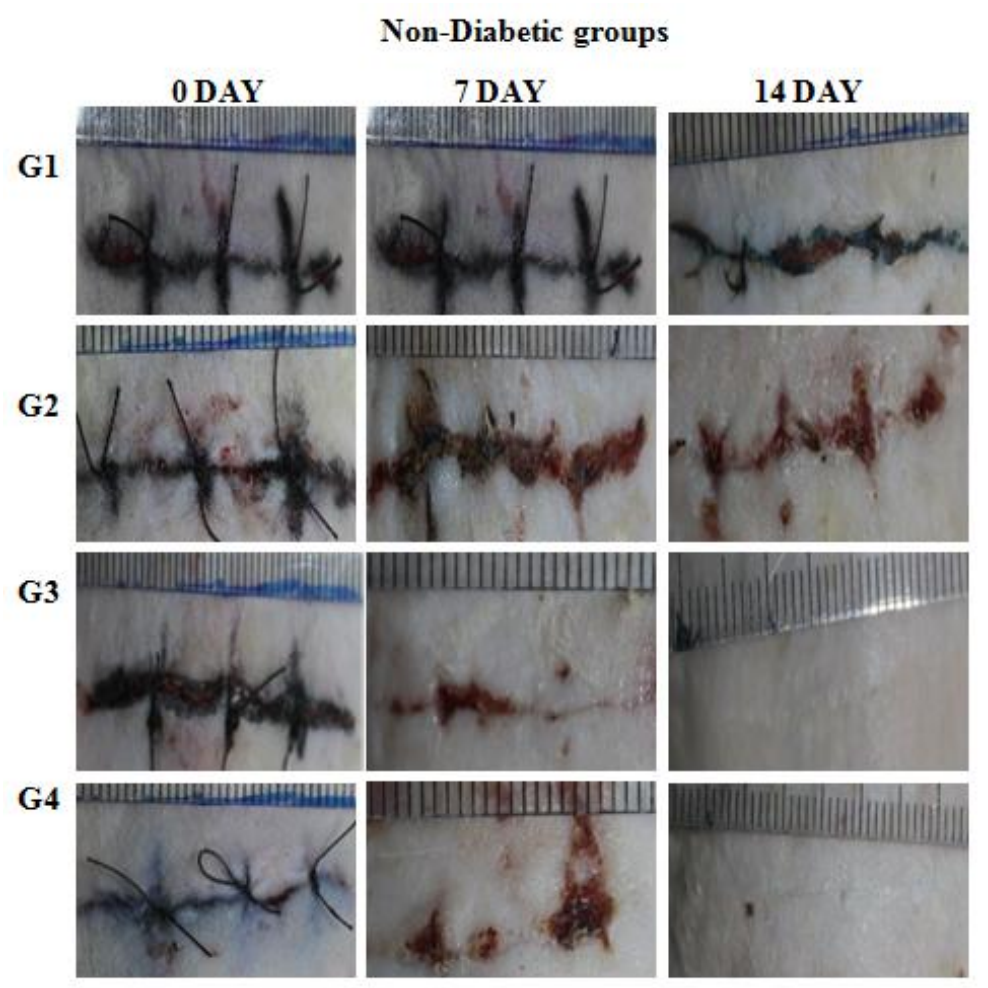

Figure 2a. Macroscopic view of incision wounds of non-diabetic groups treated with Luteolin ointments for 7 and 14 days. (G1: Control, G2: Vehicle, G3: 0.5 \% LUT, G4: $1 \%$ LUT)

Figure 2b. Macroscopic view of incision wounds of diabetic groups treated with Luteolin ointments for 7 and 14 days. (G5: DM-Control, G6: DM-Vehicle, G7: DM-0.5 \% LUT, G8: DM-1 $\%$ LUT) 
Ozay et.al., Rec. Nat. Prod. (2018) 12:4 350-366

Table 2. Wound healing ratio of two different Luteolin ointments on excision and incision wound models in non-diabetic and diabetic rats (\% contraction).

\begin{tabular}{|c|c|c|c|c|c|c|c|c|c|}
\hline & & \multicolumn{8}{|c|}{ Groups } \\
\hline & & \multicolumn{4}{|c|}{ Non-Diabetic groups } & \multicolumn{4}{|c|}{ Diabetic groups } \\
\hline & & G1 & G2 & G3 & G4 & G5 & G6 & G7 & G8 \\
\hline \multirow{4}{*}{$\begin{array}{l}\text { Application } \\
\text { Periods }\end{array}$} & Excision wound model & & & & & & & & \\
\hline & 7 Day & $\begin{array}{l}47.05 \pm 15.51^{b} \\
(29.52-65.32)\end{array}$ & $\begin{array}{l}55.02 \pm 20.03^{\mathrm{b}} \\
(26.42-74.26)\end{array}$ & $\begin{array}{c}80.4 \pm 8.7^{\mathrm{a}} \\
(62.1-89.8)\end{array}$ & $\begin{array}{c}77.2 \pm 12.7^{\mathrm{a}} \\
(61-90.8)\end{array}$ & $\begin{array}{c}26.04 \pm 9.08 \\
(10.08-36.56)\end{array}$ & $\begin{array}{c}42.88 \pm 18.52^{b} \\
(21.9-63.42)\end{array}$ & $\begin{array}{l}56.1 \pm 12.3^{a b} \\
(37.5-72.2)\end{array}$ & $\begin{array}{c}61.0 \pm 6.4^{\mathrm{a}} \\
(52.5-70.2)\end{array}$ \\
\hline & 14 Day & $\begin{array}{l}67.11 \pm 16.62^{b} \\
(40.56-86.36)\end{array}$ & $\begin{array}{l}74.72 \pm 5.88^{b} \\
(67.6-84.02)\end{array}$ & $\begin{array}{c}96.1 \pm 2.6^{\mathrm{a}} \\
(92.6-100)\end{array}$ & $\begin{array}{c}95.5 \pm 6.3^{\mathrm{a}} \\
(81.4-99.1)\end{array}$ & $\begin{array}{l}47.52 \pm 14.2 \\
(30.3-65.2)\end{array}$ & $\begin{array}{c}55.77 \pm 14.35 \\
(39.9-75.9)\end{array}$ & $\begin{array}{c}81.8 \pm 6.1^{\mathrm{ab}} \\
(73.7-88.9)\end{array}$ & $\begin{array}{c}79.5 \pm 9.5^{\mathrm{ab}} \\
(71.6-97.5)\end{array}$ \\
\hline & \multicolumn{9}{|l|}{ Incision wound model } \\
\hline Application & 7 Day & $\begin{array}{c}41.3 \pm 13.7^{b} \\
(21.6-55)\end{array}$ & $\begin{array}{c}34.2 \pm 8.3 \\
(23.1-44.7)\end{array}$ & $\begin{array}{c}64.4 \pm 8.6^{\mathrm{a}} \\
(47.6-73.7)\end{array}$ & $\begin{array}{l}65.8 \pm 5.7^{a} \\
(55.8-74)\end{array}$ & $\begin{array}{c}17.3 \pm 3.07 \\
(5.26-27.78)\end{array}$ & $\begin{array}{l}18.6 \pm 8.1 \\
(5.26-27)\end{array}$ & $\begin{array}{l}46.5 \pm 9.3^{\mathrm{ab}} \\
(34.2-61.5)\end{array}$ & $\begin{array}{l}44.2 \pm 11.1^{\mathrm{ab}} \\
(26.8-60.9)\end{array}$ \\
\hline Periods & 14 Day & $\begin{array}{c}76.4 \pm 7.5^{\mathrm{b}} \\
(66.8-84.6)\end{array}$ & $\begin{array}{c}53.4 \pm 9.4 \\
(40.4-63.8)\end{array}$ & $\begin{array}{c}97.6 \pm 2.8^{\mathrm{a}} \\
(92.9-100)\end{array}$ & $\begin{array}{l}97.4 \pm 2.4^{\mathrm{a}} \\
(93.7-100)\end{array}$ & $\begin{array}{c}71.69 \pm 6.5 \\
(60.49-78.46)\end{array}$ & $\begin{array}{c}57.1 \pm 8.8 \\
(48.2-69.8)\end{array}$ & $\begin{array}{c}89.5 \pm 10.2^{\mathrm{ab}} \\
(72.5-100)\end{array}$ & $\begin{array}{l}88.3 \pm 9.2^{\mathrm{a}} \\
(77.8-100)\end{array}$ \\
\hline
\end{tabular}

${ }^{\mathrm{a}}$ ANOVA analysis was performed. $\mathrm{P}<0.05 .{ }^{\mathrm{b}}$ ANOVA analysis was performed. $\mathrm{P}<0.01$. Measuring the average \pm SD. Min-Max value intervals were given in parenthesis. (G1: Control, G2: Vehicle, G3: 0.5 \% LUT, G4: 1 \% LUT; G5: DM-Control, G6: DM-Vehicle, G7: DM-0.5 \% LUT, G8: DM-1 \% LUT)

Table 3. Tensile strength evaluation of all tested groups in incision wound model (g/sn).

\begin{tabular}{cccccccccc}
\hline & \multicolumn{9}{c}{ Groups } \\
\hline Periods & G1 & G2 & G3 & G4 & G5 & \multicolumn{3}{c}{ Diabetic groups } & G7 \\
\hline 7 Day & $0.32 \pm 0.1$ & $0.33 \pm 0.1$ & $0.68 \pm 0.37^{\mathrm{a}}$ & $0.62 \pm 0.40^{\mathrm{a}}$ & $0.28 \pm 0.2$ & $0.31 \pm 0.6$ & $0.51 \pm 0.06^{\mathrm{b}}$ & $0.40 \pm 0.09^{\mathrm{b}}$ \\
14 Day & $0.43 \pm 0.1$ & $0.48 \pm 0.1$ & $0.93 \pm 0.34^{\mathrm{a}}$ & $0.87 \pm 0.32^{\mathrm{a}}$ & $0.48 \pm 0.1$ & $0.43 \pm 0.2$ & $0.81 \pm 0.36^{\mathrm{a}}$ & $0.77 \pm 0.45^{\mathrm{a}}$ \\
\hline
\end{tabular}

Measuring the average \pm SD and Min-Max. ${ }^{a}$ ANOVA analysis was performed. $\mathrm{P}<0.05 ;{ }^{\mathrm{b}}$ ANOVA analysis was performed. P $<0.01$. (G1:Control, G2: Vehicle,

G3: $0.5 \%$ LUT, G4: 1 \% LUT; G5: DM-Control, G6: DM-Vehicle, G7: DM-0.5 \% LUT, G8: DM-1 \% LUT) 


\subsection{Hydroxyproline Measurement}

The hydroxyproline content of non-diabetic and diabetic wound tissues on 7 and 14 days were determined and results were given in Table 4. Excision wound tissues in non-diabetic groups G3 and G4 showed significantly increasing hydroxyproline levels when compared between $7^{\text {th }}$ and $14^{\text {th }}$ days $(\mathrm{P}<0.05)$. Addition to these results, G3 group showed the highest effectiveness on 7 and 14 days with $1.54 \mu \mathrm{g} / \mathrm{mg}$ and $1.99 \mu \mathrm{g} / \mathrm{mg}$ values, respectively. When compared the diabetic groups between each other 7-day application result in G8 and 14-day application result in G7 found statistically significant with 0.63 and $0.62 \mu \mathrm{g} / \mathrm{mg}$ values, respectively $(\mathrm{P}<0.05)$.

When compared the hydroxyproline levels of incision wound tissues for 7-day application G3 and G4 in non-diabetic groups (1.34 and $1.72 \mu \mathrm{g} / \mathrm{mg}$ values respectively) and for 14-application G2 and G4 in non-diabetic and G7 in diabetic groups $(2.08,1.69$ and $0.75 \mu \mathrm{g} / \mathrm{mg}$, respectively) were considered to be statistically significant $(\mathrm{P}<0.05)$. Also incision wound study results indicated that there were no significant differences between all diabetic groups on $7^{\text {th }}$ day $(\mathrm{P}>0.05)$.

\subsection{Histopathological Study}

At the end of the experiments the tissue sections were evaluated histopathologically and study results were given in Table 5-6 and Figure 3a, 3b, 4a and 4b. Wound healing phases (inflammation, proliferation and remodeling) were viewed and noted in both non-diabetic and diabetic groups with different degrees. Histopathological study results of excision wound tissues indicated that epithelial regeneration of G3, G4 and G7 and G8 were found statistically significant to compared with control and vehicle groups of non-diabetic and diabetic animals on $7^{\text {th }}$ and $14^{\text {th }}$ days $(\mathrm{P}<0.05)$. Granulation tissue thicknesses of G4, G7 and G8 on $7^{\text {th }}$ day and G3 and G8 on $14^{\text {th }}$ day were statistically significant when compared to other tested groups $(\mathrm{P}<0.05)$. The significant differences in inflammation $(\mathrm{G} 3, \mathrm{G} 4$ and G8-day 14) and angiogenesis (G4-days 7 and 14, G3-day 14) were observed when compared to the other groups $(\mathrm{P}<0.05)$ (Table 5).

The results of incision wound model showed that epithelial regeneration of G3, G4 and G8 on both 7 and 14 days, and G7 on day 14 were statistically significant $(\mathrm{P}<0.05)$. Additionally, the significant differences in inflammation were observed in group G4 on both 7 and 14 days, and in groups G3, G7 and G8 on day 14 when compared to the other tested groups $(\mathrm{P}<0.05)$ (Table 6).

In both non-diabetic and diabetic groups, wound healing ratio of Luteolin ointments $(0.5 \%$ and $1 \%(\mathrm{w} / \mathrm{w}))$ for excision and incision wound models on $7^{\text {th }}$ and $14^{\text {th }}$ days were significantly higher than control and vehicle groups $(\mathrm{P}<0.05)$ (Table 2, Figure $2 \mathrm{a}$ and $2 \mathrm{~b})$. Ideal wound healing is confirmed with successful closure in minimum day so when compared 7-day application results, $0.5 \%$ $(\mathrm{w} / \mathrm{w})$ ointment of Luteolin caused maximum healing ratio with $80.4 \%$ value in non-diabetic excision wound model. Healing ratio of both Luteolin ointments $(0.5 \%$ and $1 \%(w / w))$ treated groups in diabetics were too closer for each excision and incision wound models for 7-day application. After 14day application wound closure ratio of Luteolin ointments treated groups was between $95.5-97.6 \%$ for non-diabetics and 79.5-89.5\% for diabetic. In our study, when compared to the non-diabetic and diabetic groups between each other, wound healing ratio of Luteolin ointments in non-diabetic found higher than diabetic. Additionally, the best wound healing activity was observed in incision wound $(97.6 \%)$ and excision wound $(96.1 \%)$ models of non-diabetic groups treated with $0.5 \%(\mathrm{w} / \mathrm{w})$ Luteolin ointment on day 14.

Previous studies demonstrated that impaired or delayed healing was serious problem in some metabolic diseases including DM $[6,8,9,10,11]$, because of several factors such as differentiation of the extracellular matrix dysfunction in fibroblasts and epidermal cells, and poor angiogenesis, e.g. $[6,11]$. Also in various studies reported that there were different repair processes between diabetic and non-diabetic wounds [9]. These findings supported that in our study why wound healing effects of Luteolin in non-diabetic were higher than diabetic. 
Tablo 4. Hydroxyproline content of wound tissues in non-diabetic and diabetic rats $(\mu \mathrm{g} / \mathrm{mg})$

\begin{tabular}{|c|c|c|c|c|c|c|c|c|c|}
\hline & & \multicolumn{8}{|c|}{ Groups } \\
\hline & & \multicolumn{4}{|c|}{ Non-Diabetic groups } & \multicolumn{4}{|c|}{ Diabetic groups } \\
\hline & & G1 & G2 & G3 & G4 & G5 & G6 & G7 & G8 \\
\hline \multicolumn{10}{|c|}{ Excision wound model } \\
\hline Application & 7 Day & $\begin{array}{l}0.44 \pm 0.15 \\
(0.19-0.56)\end{array}$ & $\begin{array}{c}0.53 \pm 0.06 \\
(0.44-0.60)\end{array}$ & $\begin{array}{c}1.54 \pm 0.39^{\mathrm{a}} \\
(1.01-2.19)\end{array}$ & $\begin{array}{l}1.46 \pm 0.40^{\mathrm{a}} \\
(1.07-2.20)\end{array}$ & $\begin{array}{c}0.23 \pm 0.12 \\
(0.02-0.37)\end{array}$ & $\begin{array}{c}0.34 \pm 0.11 \\
(0.32-0.62)\end{array}$ & $\begin{array}{c}0.37 \pm 0.25 \\
(0.12-0.89)\end{array}$ & $\begin{array}{l}0.63 \pm 0.31^{a} \\
(0.12-0.96)\end{array}$ \\
\hline Periods & 14 Day & $\begin{array}{c}0.44 \pm 0.33 \\
(0.07-0.82)\end{array}$ & $\begin{array}{c}1.36 \pm 0.09 \\
(1.19-1.43)\end{array}$ & $\begin{array}{c}1.99 \pm 0.88^{\mathrm{a}} \\
(1.02-3.76)\end{array}$ & $\begin{array}{l}1.65 \pm 0.51^{\mathrm{a}} \\
(0.86-2.28)\end{array}$ & $\begin{array}{c}0.22 \pm 0.07 \\
(0.15-0.39)\end{array}$ & $\begin{array}{c}0.14 \pm 0.04 \\
(0.08-0.20)\end{array}$ & $\begin{array}{l}0.62 \pm 0.34^{\mathrm{a}} \\
(0.25-1.21)\end{array}$ & $\begin{array}{l}0.42 \pm 0.36^{\mathrm{a}} \\
(0.12-1.11)\end{array}$ \\
\hline \multicolumn{10}{|c|}{ Incision wound model } \\
\hline Application & 7 Day & $\begin{array}{l}0.16 \pm 0.12 \\
(0.04-0.35)\end{array}$ & $\begin{array}{c}0.64 \pm 0.44 \\
(0.29-1.38)\end{array}$ & $\begin{array}{c}1.34 \pm 0.25^{\mathrm{a}} \\
(1.04-1.69)\end{array}$ & $\begin{array}{l}1.72 \pm 0.38^{\mathrm{ab}} \\
(1.36-2.49)\end{array}$ & $\begin{array}{c}0.08 \pm 0.03 \\
(0.04-0.16)\end{array}$ & $\begin{array}{c}0.31 \pm 0.25 \\
(0.03-0.66)\end{array}$ & $\begin{array}{c}0.35 \pm 0.28 \\
(0.13-0.86)\end{array}$ & $\begin{array}{c}0.40 \pm 0.16 \\
(0.22-0.75)\end{array}$ \\
\hline Periods & 14 Day & $\begin{array}{c}0.35 \pm 0.30 \\
(0.08-0.67)\end{array}$ & $\begin{array}{l}2.08 \pm 0.20^{\mathrm{a}} \\
(1.83-2.40)\end{array}$ & $\begin{array}{l}1.60 \pm 0.43^{\mathrm{a}} \\
(0.97-2.25)\end{array}$ & $\begin{array}{l}1.69 \pm 0.33^{\mathrm{a}} \\
(1.30-2.10)\end{array}$ & $\begin{array}{c}0.30 \pm 0.10 \\
(0.09-0.40)\end{array}$ & $\begin{array}{c}0.36 \pm 0.19 \\
(0.05-0.27)\end{array}$ & $\begin{array}{l}0.75 \pm 0.48^{\mathrm{a}} \\
(0.27-1.39)\end{array}$ & $\begin{array}{l}0.63 \pm 0.50^{b} \\
(0.22-1.41)\end{array}$ \\
\hline
\end{tabular}

Measuring the average \pm SD and Min-Max value intervals were given in parenthesis. ${ }^{\mathrm{a}}$ ANOVA analysis was performed. $\mathrm{P}<0.05$; ${ }^{\mathrm{b}}$ ANOVA analysis was performed. $\mathrm{P}<0.01$. (G1: Control, G2: Vehicle, G3: $0.5 \%$ LUT, G4: $1 \%$ LUT; G5: DM-Control, G6: DM-Vehicle, G7: DM-0.5 \% LUT, G8: DM-1 \% LUT)

Tablo 5. Histological scores of groups in excision wound model. 


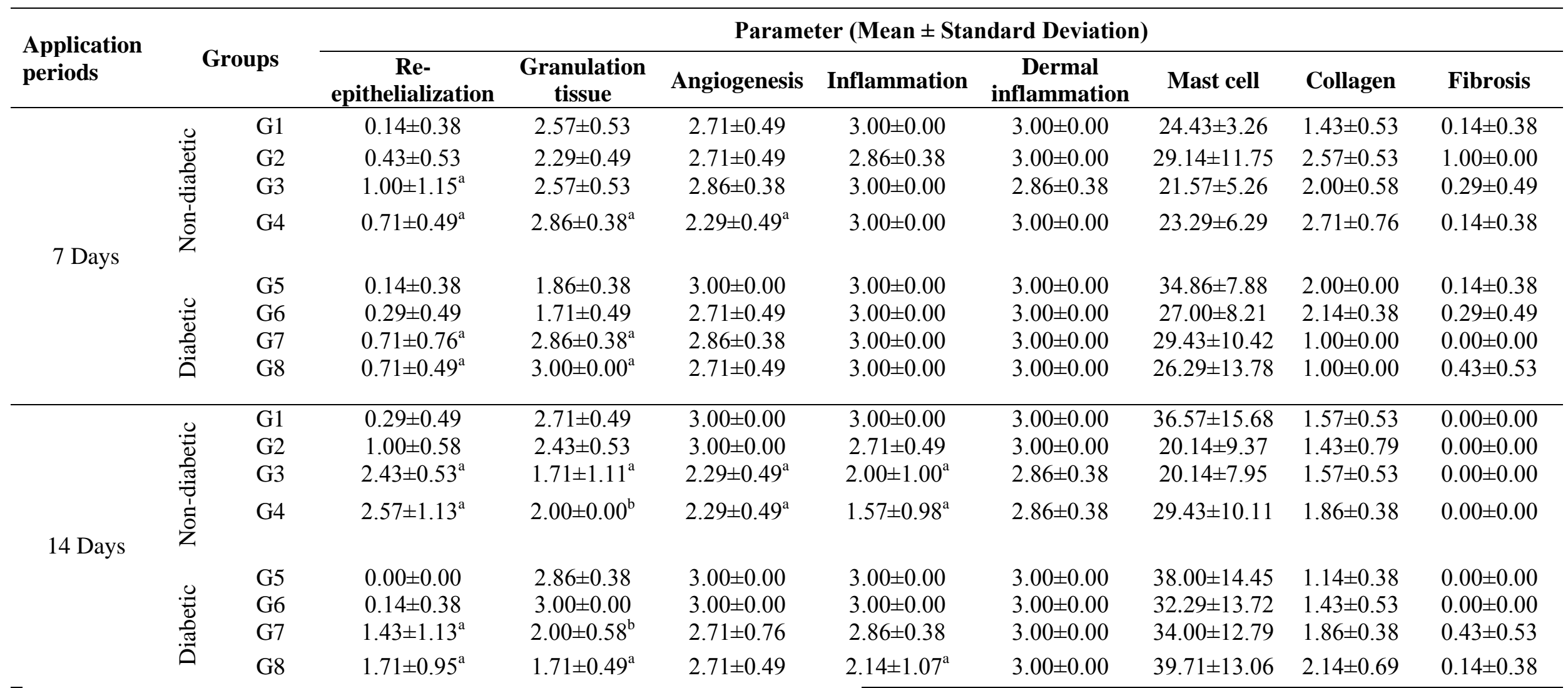

Measuring the average \pm SD and Min-Max. ${ }^{a}$ ANOVA analysis was performed $\mathrm{P}<0.05 .{ }^{\mathrm{b}}$ ANOVA analysis was performed. P $<0.01$ (G1: Control, G2: Vehicle, G3: $0.5 \%$ LUT, G4: 1 \% LUT; G5: DM-Control, G6: DM-Vehicle, G7: DM-0.5 \% LUT, G8: DM-1 \% LUT)

Tablo 6. Histological scores of groups in incision wound model. 


\begin{tabular}{|c|c|c|c|c|c|c|c|c|c|c|}
\hline \multirow{2}{*}{$\begin{array}{l}\text { Application } \\
\text { periods }\end{array}$} & \multirow{2}{*}{\multicolumn{2}{|c|}{ Groups }} & \multicolumn{8}{|c|}{ Parameter (Mean \pm Standard Deviation) } \\
\hline & & & $\begin{array}{c}\text { Re- } \\
\text { epithelialization }\end{array}$ & $\begin{array}{c}\text { Granulation } \\
\text { tissue }\end{array}$ & Angiogenesis & Inflammation & $\begin{array}{c}\text { Dermal } \\
\text { inflammation }\end{array}$ & Mast cell & Collagen & Fibrosis \\
\hline \multirow{8}{*}{7 Days } & \multirow{4}{*}{ 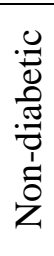 } & G1 & $1.71 \pm 0.95$ & $0.86 \pm 0.38$ & $2.57 \pm 0.79$ & $2.57 \pm 0.79$ & $2.28 \pm 1.25$ & $34.43 \pm 10.83$ & $2.14 \pm 0.69$ & $0.00 \pm 0.00$ \\
\hline & & $\mathrm{G} 2$ & $2.29 \pm 0.95$ & $1.29 \pm 0.49$ & $1.86 \pm 0.49$ & $2.29 \pm 0.49$ & $2.00 \pm 0.82$ & $23.14 \pm 8.36$ & $1.29 \pm 0.49$ & $0.29 \pm 0.49$ \\
\hline & & G3 & $2.86 \pm 0.38^{\mathrm{a}}$ & $1.43 \pm 0.79$ & $2.00 \pm 1.00$ & $1.86 \pm 0.90$ & $2.86 \pm 0.38$ & $18.14 \pm 12.02$ & $2.29 \pm 0.55$ & $0.29 \pm 0.49$ \\
\hline & & G4 & $3.00 \pm 0.00^{\mathrm{a}}$ & $1.00 \pm 0.00$ & $1.43 \pm 1.13$ & $1.29 \pm 0.76^{\mathrm{a}}$ & $2.29 \pm 0.49$ & $15.14 \pm 3.67$ & $1.71 \pm 0.49$ & $0.00 \pm 0.00$ \\
\hline & \multirow{4}{*}{ 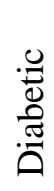 } & G5 & $1.71 \pm 1.38$ & $1.00 \pm 1.15$ & $1.43 \pm 0.79$ & $2.29 \pm 0.95$ & $2.29 \pm 0.76$ & $20.14 \pm 8.15$ & $1.29 \pm 0.76$ & $0.14 \pm 0.38$ \\
\hline & & G6 & $1.57 \pm 1.27$ & $0.71 \pm 0.49$ & $2.14 \pm 0.90$ & $2.29 \pm 0.95$ & $2.71 \pm 0.49$ & $21.14 \pm 7.86$ & $1.29 \pm 0.95$ & $0.00 \pm 0.00$ \\
\hline & & G7 & $1.43 \pm 0.98$ & $1.86 \pm 0.38$ & $2.14 \pm 0.69$ & $3.00 \pm 0.00$ & $3.00 \pm 0.00$ & $16.14 \pm 4.41$ & $1.29 \pm 0.76$ & $0.00 \pm 0.00$ \\
\hline & & G8 & $2.14 \pm 0.90^{\mathrm{a}}$ & $1.57 \pm 0.53$ & $2.29 \pm 0.76$ & $2.71 \pm 0.49$ & $3.00 \pm 0.00$ & $19.71 \pm 10.05$ & $1.71 \pm 0.76$ & $0.29 \pm 0.49$ \\
\hline \multirow{8}{*}{14 Days } & \multirow{4}{*}{ 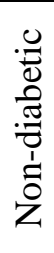 } & G1 & $2.29 \pm 0.95$ & $0.43 \pm 0.53$ & $1.86 \pm 1.07$ & $1.71 \pm 0.95$ & $2.14 \pm 0.12$ & $24.00 \pm 12.60$ & $2.71 \pm 0.49$ & $0.14 \pm 0.38$ \\
\hline & & $\mathrm{G} 2$ & $2.14 \pm 1.07$ & $1.14 \pm 0.38$ & $1.71 \pm 1.25$ & $1.57 \pm 0.98$ & $2.00 \pm 1.15$ & $13.29 \pm 4.42$ & $2.57 \pm 0.79$ & $0.00 \pm 0.00$ \\
\hline & & G3 & $3.00 \pm 0.00^{\mathrm{a}}$ & $0.43 \pm 0.79$ & $1.57 \pm 0.98$ & $1.00 \pm 0.00^{\mathrm{a}}$ & $1.14 \pm 0.21$ & $25.43 \pm 8.46$ & $0.86 \pm 0.69$ & $0.29 \pm 0.49$ \\
\hline & & G4 & $3.00 \pm 0.00^{\mathrm{a}}$ & $0.43 \pm 0.53$ & $0.86 \pm 0.38$ & $1.00 \pm 0.58^{\mathrm{a}}$ & $2.29 \pm 0.49$ & $14.57 \pm 7.63$ & $1.71 \pm 1.25$ & $0.00 \pm 0.00$ \\
\hline & \multirow{4}{*}{ 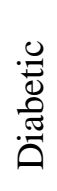 } & G5 & $1.86 \pm 1.35$ & $1.57 \pm 0.53$ & $2.00 \pm 0.82$ & $1.86 \pm 0.90$ & $2.86 \pm 0.38$ & $20.86 \pm 9.25$ & $2.14 \pm 0.90$ & $0.00 \pm 0.00$ \\
\hline & & G6 & $2.00 \pm 0.82$ & $2.14 \pm 0.69$ & $2.00 \pm 0.82$ & $2.00 \pm 0.82$ & $3.00 \pm 0.00$ & $31.29 \pm 16.32$ & $2.00 \pm 0.82$ & $0.00 \pm 0.00$ \\
\hline & & G7 & $3.00 \pm 0.00^{\mathrm{a}}$ & $0.14 \pm 0.38$ & $1.00 \pm 0.00$ & $1.00 \pm 0.00^{\mathrm{a}}$ & $3.00 \pm 0.00$ & $21.29 \pm 4.86$ & $1.57 \pm 0.53$ & $0.00 \pm 0.00$ \\
\hline & & G8 & $3.00 \pm 0.00^{\mathrm{a}}$ & $0.14 \pm 0.38$ & $1.00 \pm 0.58$ & $0.86 \pm 0.38^{\mathrm{a}}$ & $2.57 \pm 1.13$ & $26.29 \pm 6.16$ & $0.86 \pm 0.38$ & $0.00 \pm 0.00$ \\
\hline
\end{tabular}

Measuring the average \pm SD and Min-Max. ${ }^{a}$ ANOVA analysis was performed $\mathrm{P}<0.05 .{ }^{\mathrm{b}} \mathrm{ANOVA}$ analysis was performed. P<0.01 (G1: Control, G2: Vehicle, G3: $0.5 \%$ LUT, G4: 1 \% LUT; G5: DM-Control, G6: DM-Vehicle, G7: DM-0.5 \% LUT, G8: DM-1 \% LUT) 


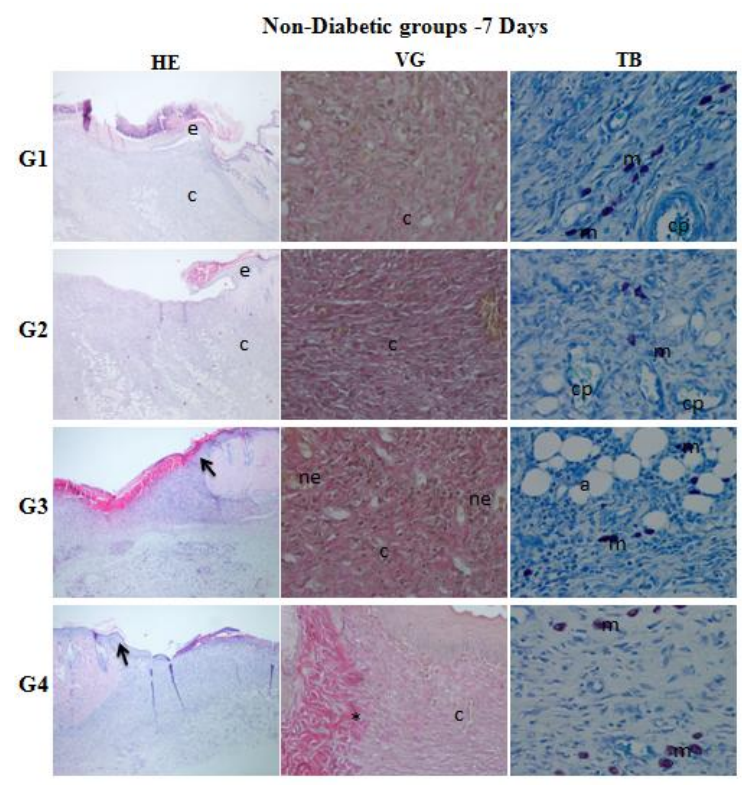

Figure 3a. Histopathological evaluation of wound healing and epidermal/dermal re-modeling in the non-diabetic rats for 7 days. (HE: Skin section stained epidermis and dermis with hematoxylin\&eosin (x400), VG: Skin section stained dermis with Van Gieson (x400), TB: Skin section stained with Toluidine blue $(\mathrm{x} 40)$. e: epithelium, c: connective tissue, $\rightarrow$ : reepithelialization, nv: neovascularization, co: collagen, asteriks: granulation tissue, m: mast cells, cp: capillaries, a: adipose tissue, h: hair follicules (G1: Control, G2: Vehicle, G3: $0.5 \%$ LUT, G4: $1 \%$ LUT)

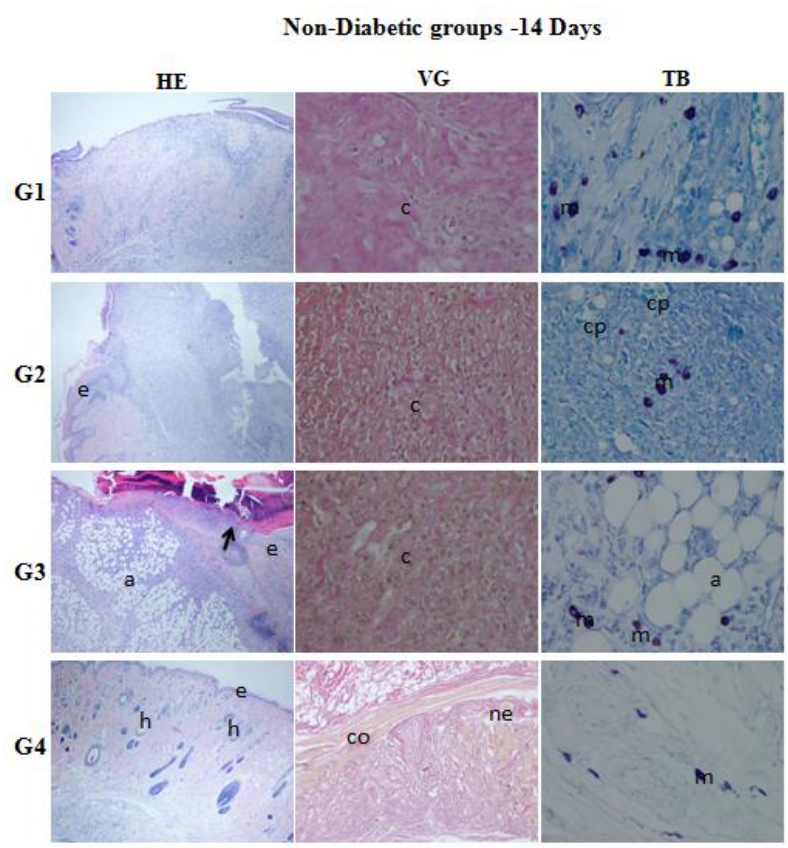

Figure 3b. Histopathological evaluation of wound healing and epidermal/dermal re-modeling in the non-diabetic rats for 14 days. (HE: Skin section stained epidermis and dermis with hematoxylin\&eosin (x400), VG: Skin section stained dermis with Van Gieson (x400), TB: Skin section stained with Toluidine blue $(\mathrm{x} 40)$. e: epithelium, c: connective tissue, $\rightarrow$ : reepithelialization, nv: neovascularization, co: collagen, asteriks: granulation tissue, m: mast cells, cp: capillaries, a: adipose tissue, h: hair follicules (G1: Control, G2: Vehicle, G3: $0.5 \%$ LUT, G4: $1 \%$ LUT) 


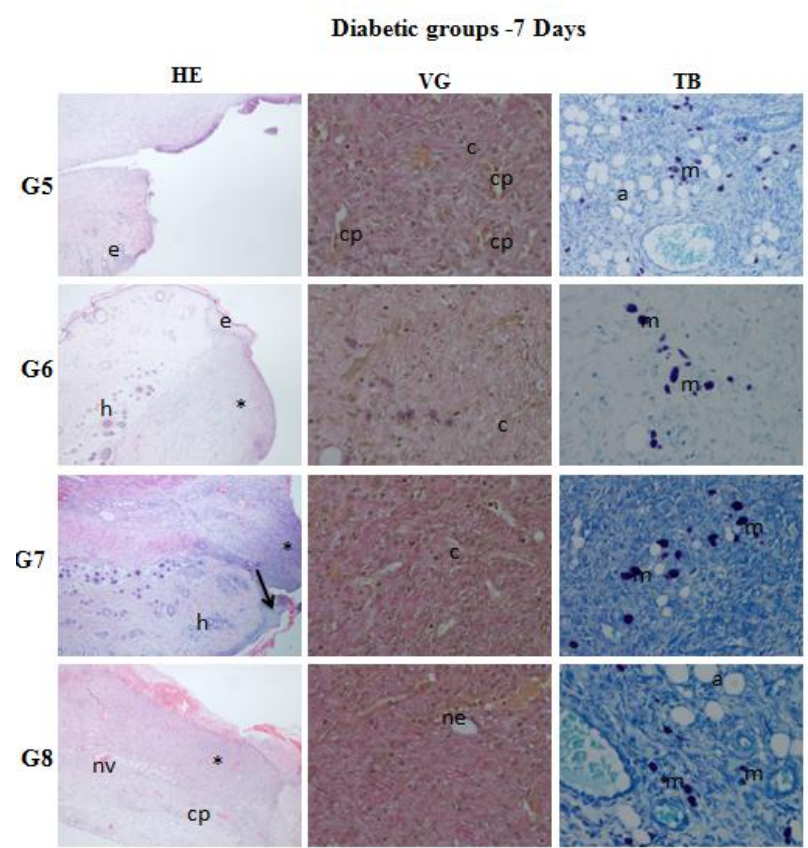

Figure 4a. Histopathological evaluation of wound healing and epidermal/dermal re-modeling in the diabetic rats for 7 days. (HE: Skin section stained epidermis and dermis with hematoxylin\&eosin (x400), VG: Skin section stained dermis with Van Gieson (x400), TB: Skin section stained with Toluidine blue (x40). e: epithelium, c: connective tissue, $\rightarrow$ : re-epithelialization, nv: neovascularization, co: collagen, asteriks: granulation tissue, m: mast cells, cp: capillaries, a: adipose tissue, h: hair follicules (G5: DM-Control, G6:DM-Vehicle, G7: DM-0.5 \% LUT, G8: DM-1 \% LUT)

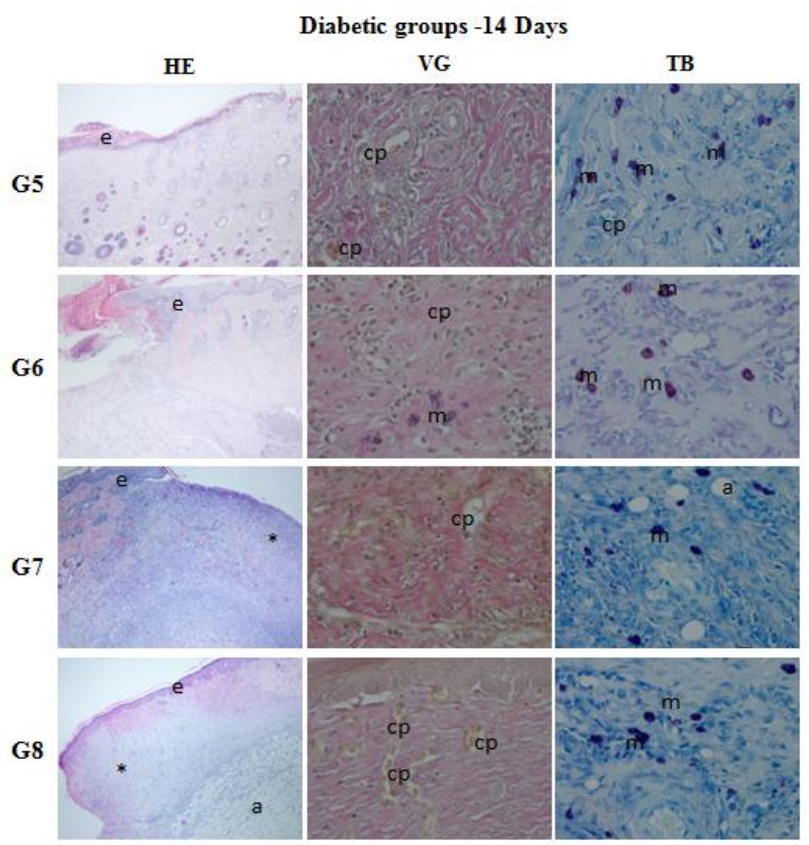

Figure 4b. Histopathological evaluation of wound healing and epidermal/dermal re-modeling in the diabetic rats for 14 days. (HE: Skin section stained epidermis and dermis with hematoxylin\&eosin (x400), VG: Skin section stained dermis with Van Gieson (x400), TB: Skin section stained with Toluidine blue (x40). e: epithelium, c: connective tissue, $\rightarrow$ : reepithelialization, nv: neovascularization, co: collagen, asteriks: granulation tissue, m: mast cells, cp: capillaries, a: adipose tissue, h: hair follicules (G5: DM-Control, G6:DM-Vehicle, G7: DM-0.5 \% LUT, G8: DM-1 \% LUT) 
Tensile strength, is an important parameter because of reflecting the subdermal organization of the collagen fibers in the newly deposited collagen [13]. Biomechanical study results indicated that tensile strength of non-diabetic groups treated with Luteolin ointments $(0.5 \%$ and $1 \%(\mathrm{w} / \mathrm{w}))$ on days 7 and 14 were statically significant when compared with control and vehicle groups $(p<0.05)$. Additionally, tensile strength of diabetic group treated with Luteolin ointments showed significant differences than control and vehicle.

Re-epithelialization, angiogenesis, thickness of granulation tissue, degree of inflammation, number of mast cells, extent of dermal inflammation, presence of fibrosis and collagen deposition were studied for histopathological evaluation and histopathological changes on the excision and incision wound models treated with Luteolin ointments in non-diabetic and diabetic rats on day 7 and 14 were observed. In both wound models, Luteolin ointments $(0.5 \%$ and $1 \%(\mathrm{w} / \mathrm{w}))$ showed epithelization induction.

Addition to the results of macroscopical, biomechanical and histopatolocigal studies, measurement of hydroxyproline levels indicated that Luteolin ointments have successful healing effects on excisional and incisional wounds in both non-diabetic and diabetic rats. The increased hydroxyproline content is evidence of rapid wound healing [6, 34].

Wound healing that results in wound contraction, wound closure and restoration of the functional barrier is complex process $[4,34]$. Hemostasis, inflammation, proliferation and remodeling are important steps of this process $[6,13,14]$. Previous studies indicated that because of hydroxyl moieties and 2-3 carbon double bond in molecule structure is responsible from Luteolin's several activities [18,19] including anti-inflammatory, antioxidant $[6,18,19,20,22]$ and antimicrobial $[5,19,22]$ which effected wound healing process positively [35]. Therefore, healing potential of Luteolin in persistent dermal wounds such as chronic wounds or ulcers can be supported by these activities and also explain effectiveness of Luteolin ointments on excision and incision wound models in nondiabetic and diabetic rats in our study. Lodhi et. al. (2013 and 2016) investigated wound healing effect of two different concentrations $(0.2$ and $0.5 \%(w / w))$ of Luteolin isolated from Martynia annua Linn. $[6,36]$ on excision wound model in diabetic rats for 18 days [6] on dead-space and burn wound models in non-diabetic rats for 9 and 18 days, respectively [36]. Also in both studies ointments were topically applied twice daily $[6,36]$ and histopathological changes on 18th day $[6,36]$ and on 9th day [36] indicated that $0.5 \%$ Luteolin ointment had healing effect. So these results supported our findings. Processes of healing phases are depended on type of damage, and thus type of wound models such as excision, incision, dead-space, burn e.g. are affected healing stages differently [37]. In the present study, the efficiency of Luteolin ointments $(0.5 \%$ and $1 \%(\mathrm{w} / \mathrm{w}))$ on both excision and incision wound models were tested for 7 and 14 days and all macroscopical, biomechanical, biochemical and histopathological changes on days 7 and 14 were examined. Experiments were performed for shorter time with lower daily application dose than previous studies. In diabetic and non-diabetic rats, $0.5 \%$ and $1 \%(\mathrm{w} / \mathrm{w})$ concentrations of Luteolin were firstly tested on incision wound model and also $1 \%$ $(\mathrm{w} / \mathrm{w})$ concentration was firstly tested on both excision and incision wound models. The study results indicated that increasing concentration of Luteolin was not influenced wound healing efficiency on tested wound models in both diabetic and non-diabetic rats.

In conclusion, wound healing phenomenon was well orchestrated in both non-diabetic and diabetic groups by Luteolin in our study. Many medicinal plants are rich for Luteolin content and adverse effects of synthetic drugs with expensive costs needed to discover new source of drugs. In this study wound healing potential of Luteolin was determined by evaluating various parameters on excision and incision wounds in both non-diabetic and diabetic animals and our findings demonstrated that Luteolin can be used as a wound healing agent for different wound types. So further studies are needed to determine the pathways of action mechanisms of Luteolin which is responsible from its wound healing processes.

\section{Acknowledgements}

This study was supported by Research Projects Department of Ahi Evran University with grant no: PYO-SAG.4001.12.002. 


\section{ORCID}

Yusuf Ozay: 0000-0003-3855-6197

Sevda Guzel: 0000-0002-6642-5824

Ibrahim Halil Erdogdu: 0000-0002-5445-2649

Zuhal Yildirim: 0000-0002-2808-7860

Burcin Pehlivanoglu: 0000-0001-6535-8845

Bilge AydınTurk: 0000-0003-1592-1040

Sinan Darcan: 0000-0002-2135-4807

\section{References}

[1] J. Wedler, T. Daubitz, G. Schlotterbeck and V. Butterweck (2014). In vitro anti-inflammatory and wound-healing potential of a Phyllostachys edulis leaf extract-identification of isoorientin as an active compound, Planta Med. 80, 1678-1684.

[2] L. T. Fox, A. Mazumder, A. Dwivedi, M. Gerber, J. Plessis and J. H. Hamman (2017). In vitro wound healing and cytotoxic activity of the gel and whole-leaf materials from selected Aloe species, $J$. Ethnopharmacol. 200, 1-7.

[3] J. Kim and C. M. Lee (2017). Wound healing potential of a polyvinyl alcohol-blended pectin hydrogel containing Hippophae rahmnoides L. extract in a rat model, Int. J. Biol. Macromol. 99, 586-593.

[4] U. Das, S. S. Behera and K. Pramanik (2017). Ethno-herbal-medico in wound repair: an incisive review, Phytother. Res. 31, 579-590.

[5] X. Su, X. Liu, S. Wang, B. Li, T. Pan, D. Liu, F. Wang, Y. Diao and K. Li (2017). Wound-healing promoting effect of total tannins from Entada phaseoloides (L.) Merr. in rats, Burns. 43, 830-838.

[6] S. Lodhi and A. K. Singhai (2013). Wound healing effect of flavonoid rich fraction and luteolin isolated from Martynia annua Linn. on streptozotocin induced diabetic rats, Asian Pac. J. Trop. Med. 253-259.

[7] A. Budovsky, L. Yarmolinsky and S. Ben-Shabat (2015). Effect of medicinal plants on wound healing, Wound Repair Regen. 23 (2), 171-183.

[8] S. Babaei, H. Ansarihadipour, M. Nakhaei, M. Darabi, P. Bayat, M. Sakhaei, M. Baazm and A. Mohammadhoseiny (2017). Effect of Omegaven on mast cell concentration in diabetic wound healing, J. Tissue Viability. 26, 125-130.

[9] X. Y. Ji, Y. Chen, G. H. Ye, M. W. Dong, K. Z. Lin, J. G. Han, X. P. Feng, X. B. Li, L. S. Yu and Y. Y. Fan (2017). Detection of RAGE expression and its application to diabetic wound age estimation, Int. J. Legal Med. 131, 691-698.

[10] P. S. Rabbani, A. Zhou, Z. M. Borab, J. A. Frezzo, N. Srivastava, H. T. More, W. J. Rifkin, J. A. David, S. J. Berens, R. Chen, S. Hameedi, M. H. Junejo, C. Kim, R. A. Sartor, C. F. Liu, P. B. Saadeh, J. K. Montclare and D. J. Ceradini (2017). Novel lipoproteoplex delivers Keap1 siRNA based gene therapy to accelerate diabetic wound healing, Biomaterials. 132, 1-15.

[11] I. Frangez, K. Cankar, H. B. Frangez and D. M. Smrke (2017). The effect of LED on blood microcirculation during chronic wound healing in diabetic and non-diabetic patients-a prospective, double-blind randomized study, Lasers Med. Sci. 32, 887-894.

[12] A. Kasuya and Y. Tokura (2014). Attempts to accelerate wound healing, J. Dermatol. Sci. 76, 169-172.

[13] T. K. Biswas, S. Pandit, S. Chakrabarti, S. Banerjee, N. Poyra and T. Seal (2017). Evaluation of Cynodon dactylon for wound healing activity, J. Ethnopharmacol. 197, 128-137.

[14] I. Garcia-Orue, G. Gainza, F. B. Gutierrez, J. J. Aguirre, C. Evora, J. L. Pedraz, R. M. Hernandez, A. Delgado and M. Igartua (2017). Novel nanofibrous dressings containing rhEGF and Aloe vera for wound healing applications, Int. J. Pharm. 523, 556-566.

[15] S. Negahdari, H. Galehdari, M. Kesmati, A. Rezaie and G. Shariati (2017). Wound healing activity of extracts and formulations of Aloe vera, Henna, Adiantum capillus-veneris, and Myrrh on mouse dermal fibroblast cells, Int. J. Prev. Med. 8, 18-27.

[16] J. Y. Park, Y. K. Lee, D. S. Lee, J. E. Yoo, M. S. Shin, N. Yamabe, S. N. Kim, S. Lee, K. H. Kim, H. J. Lee, S. S. Roh and K. S. Kanga (2017). Abietic acid isolated from pine resin (Resina Pini) enhances angiogenesis in HUVECs and accelerates cutaneous wound healing in mice, J. Ethnopharmacol. 203, 279-287.

[17] M. Jridi, S. Sellimi, K. B. Lassoued, S. Beltaief, N. Souissi, L. Mora, F. Toldra, A. Elfeki, M. Nasri and R. Nasri (2017). Wound healing activity of cuttlefish gelatin gels and films enriched byhenna (Lawsonia inermis) extract, Colloids Surf. A. Physicochem. Eng. Asp. 512, 71-79.

[18] S. F. Nabavi, N. Braidy, O. Gortzi, E. Sobarzo-Sanchez, M. Daglia, K. Skalicka-Wozniak and S. M. Nabavi (2015). Luteolin as an anti-inflammatory and neuro-protective agent: A brief review, Brain Res. 
Bull. 119, 1-11.

[19] A. K. Pandurangan and N. M. Esa (2014). Luteolin, a bioflavonoid inhibits colorectal cancer through modulation of multiple signaling pathways: A Review. Asian Pac. J. Cancer Prev. 15, 5501-5508.

[20] L. Verschooten, K. Smaers, S. V. Kelst, C. Proby, D. Maes, L. Declercq, P. Agostinis and M. Garmyn (2010). The flavonoid luteolin increases the resistance of normal, but not malignant keratinocytes, against UVB-induced apoptosis, J. Invest. Dermatol. 130, 2277-2285.

[21] G. Seelinger, I. Merfort, U. Wölfle and C. M. Schempp (2008). Anti-carcinogenic effects of the flavonoid Luteolin, Molecules. 13, 2628-2651.

[22] T. Xu, D. Li and D. Jiang (2012). Targeting cell signaling and apoptotic pathways by Luteolin: cardioprotective role in rat cardiomyocytes following ischemia/reperfusion, Nutrients. 4, 2008-2019.

[23] I. Suntara, E. Kupeli Akkol, H. Keles, E. Yesilada, S. D. Sarker, R. Arroo and T. Baykal (2012). Efficacy of Daphne oleoides subsp. kurdica used for wound healing: Identification of active compounds through bioassay guided isolation technique, J. Ethnopharmacol. 141, 1058-1070.

[24] Z. Luo, B. S. Murray, A. Yusoff, M. R. A. Morgan, M. J. W. Povey and A. J. Day (2011). Particlestabilizing effects of flavonoids at the oil-water interface, J. Agric. Food Chem. 59, 2636-2645.

[25] S. Kitagawa, R. Yutani, R. Kodani and R. Teraoka (2016). Differences in the rheological properties and mixing compatibility with heparinoid cream of brand name and generic steroidal ointments: The effects of their surfactants, Results Pharma Sci. 6, 7-14.

[26] Y. Ozay, M.S. Ozyurt, S. Guzel, A. Cimbız, E. G. Olgun and K. Cayc1 (2010). Effects of Equisetum arvense ointment on dermal wound healing in rats, Wounds. 22(10), 261-267.

[27] S. Lodhi and A. K. Singhai (2011). Preliminary pharmacological evaluation of Martynia annua Linn leaves for wound healing, Asian Pacif. J. Trop. Biomed. 1(6), 421-427.

[28] A .B. Hernandez-Hernandez, F. J. Alarcon-Aguilar, J. C. Almanza-Perez, O. Nieto-Yañez, J. M. Olivares-Sanchez, A. Duran-Diaz, M. A. Rodriguez-Monroy and M. M. Canales-Martinez (2017). Antimicrobial and anti-inflammatory activities, wound-healing effectiveness and chemical characterization of the latex of Jatropha neopauciflora Pax, J. Ethnopharmacol. 204, 1-7.

[29] M. S. Bitar (1998). Glucocorticoid dynamics and impaired wound healing in Diabetes mellitus, Am. J. Pathol. 152(2), 547-554.

[30] R. M. P. Gutierrez and S. R. Vargas (2006). Evaluation of the wound healing properties of Acalypha langiana in diabetic rats, Fitoterapia 77, 286-289.

[31] I. S. Jamall, V. N. Finelli and S. S. Que-Hee (1981). A simple method to determine nanogram levels of 4-hydroxyproline in biological tissues, Anal Biochem. 112(1), 70-75.

[32] G. L. Kumar (2010). Special Stains and H\&E Second edition, Dako Press, California, USA.

[33] M. Khoshneviszadeh, S. Ashkani-Esfahani, M. R. Namazi, A. Noorafshan, B. Geramizadeh and R. Miri (2014). Topical simvastatin enhances tissue regeneration in full-thickness skin wounds in rat models, Iran J. Pharm. Res. 13(1), 263-269.

[34] Y. Abramov, B. Golden, M. Sullivan, S. Botros, J. Miller, A. Alshahrour, R. Goldberg and P. Sand (2007). Histologic characterization of vaginal vs. abdominal surgical wound healing in a rabbit model, Wound Repair Regen. 15, 80-86.

[35] O. A. Cetinkaya (2010). Effect of Statins in wound healing on rats, Thesis. Ankara University Faculty of Medicine, Department of Surgery.

[36] S. Lodhi, A. Jain, A.P. Jain, R.S. Pawar and A.K. Singhai (2016). Effects of flavonoids from Martynia annua and Tephrosia purpurea on cutaneous wound healing, Avicenna J. Phytomed. 6 (5), 578-591.

[37] K. V. Ananth, M. Asad, N. P. Kumar, S. M. B. Asdaq and G. S. Rao (2010). Evaluation of wound healing potential of Bauhinia purpurea leaf extracts in rats, Indian J. Pharm. Sci. 72(1), 122-127.

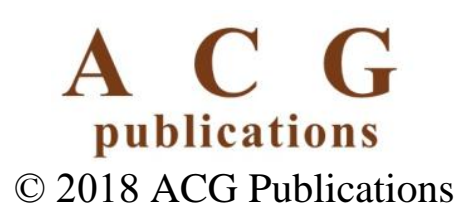

